\title{
BIODIVERSIDADE, DIREITOS E PRODUÇÃO CAMPONESA DE ALIMENTOS
}

\author{
BIODIVERSITY, RIGHTS AND PEASANT FOOD PRODUCTION
}

\author{
Carlos Frederico Marés de Souza Filho* \\ Thais Giselle Diniz Santos** \\ Flavia Donini Rossito ${ }^{* * *}$
}

\begin{abstract}
Resumo: A conservação da biodiversidade consiste em uma das mais importantes questões ambientais do século XXI. O artigo analisa a contradição existente e expressa pelo Direito entre proteção e conservação da biodiversidade e desenvolvimento da biotecnologia. Em tese, o desenvolvimento da biotecnologia deveria favorecer a conservação da biodiversidade, mas da maneira em que está sendo utilizado, não conserva. $\mathrm{O}$ Direito, protetor da propriedade individual, se vê na contingência de proteger a biodiversidade como direito da coletividade que se confronta com os direitos individuais. A análise desta antinomia se faz a partir dos conceitos sociojurídicos de biodiversidade e sua conservação ex situ ou in situ, extraídos da Lei n. 13.123/15 e da Convenção de Diversidade Biológica (CDB). A opção por uma ou outra forma prevalente de conservação leva a situações opostas e de grandes riscos para a produção de alimentos e para a biodiversidade. Fica demonstrada a importância da conservação in situ para a proteção da biodiversidade, assim como que tal estratégia é possível a partir da conservação, multiplicação e diversificação da produção camponesa e de povos tradicionais. A produção camponesa baseada em consciência e organização protege a biodiversidade, como fica claro em muitas iniciativas do MST e nas Jornadas de Agroecologia. Com isso passa a ser possível não só a proteção da biodiversidade, mas a produção de alimentos saudáveis em quantidade para a promoção da soberania alimentar da população, que devem ser apoiadas pela biotecnologia.
\end{abstract}

Palavras-chave: Direito Socioambiental; Biodiversidade; Conflitos Socioambientais; Sementes Crioulas; Agricultor Tradicional.

\begin{abstract}
Biodiversity conservation is one of the most important environmental issues of the 21 st century. In view of this, this article analyzes the contradiction existing and expressed by the Law between protection and conservation of biodiversity and biotechnology development. In theory, the development of biotechnology
\end{abstract}

\footnotetext{
* Possui graduação em Direito pela Universidade Federal do Paraná (1969), mestrado em Direito pela Universidade Federal do Paraná (1988 - Proteção Jurídica dos Bens Culturais) e doutorado em Direito pela Universidade Federal do Paraná (1998 - Direito dos Povos Indígenas) Integra o Programa de Mestrado e Doutorado da Pontifícia Universidade Católica do Paraná, onde é professor titular de Direito Agrário e Socioambiental, Professor do Mestrado, Doutorado e Graduação em Direito. E-mail: carlosmares@terra. com.br

** Doutoranda em Direitos Humanos e Democracia pela Universidade Federal do Paraná (2019). Mestra em Meio Ambiente e Desenvolvimento pelo Programa de Pós-Graduação em Meio Ambiente e Desenvolvimento da UFPR (PPGMADE-UFPR). Pesquisadora do grupo "Ekoa: direito, movimentos sociais e natureza". Bacharela em Direito pela UFPR, habilitação em Teoria do Direito e Direitos Humanos. Participou de programa de Mobilidade Acadêmica na Université Paris-Sorbonne no ano de 2013. Realizou iniciação científica pelo Grupo de Pesquisa "Instituições Políticas e Processo Legislativo (CNPQ)", na linha "Ensino Jurídico de Direito Agrário". E-mail: thaisgisellediniz@gmail.com

*** Doutoranda em Meio Ambiente e Desenvolvimento pela Universidade Federal do Paraná (Bolsista CNPq). Mestre em Direito Agroambiental pela Universidade Federal de Mato Grosso. Especialista em Direito do Trabalho e Processual do Trabalho pela Escola Paulista de Direito. Graduada em Direito pelo Centro Universitário Eurípides de Marília. E-mail: flaviarossito@gmail.co
} 
should favor the conservation of biodiversity, but by the way it has being used, it does not conserve. The Law, protector of individual property, is seen in the contingency of protecting biodiversity as a collectivity right that is confronted with individual rights. The analysis of this antinomy is based on socio-juridical concepts of biodiversity and its ex situ or in situ conservation, extracted from the Law n. 13.123/15 and the Convention on Biologic Diversity (CBD). The choice for one or other prevailing form of conservation leads to opposite situations and great risks for food production and for biodiversity. It is demonstrated the importance of the in situ conservation for the biodiversity protection, as well that this strategy is possible from the conservation, multiplication and diversification of peasant production and traditional peoples. Peasant production based on awareness and organization protects the biodiversity, as is clear from many MST initiatives and the Agroecology Journeys. This will enable not only the protection of biodiversity, but the production of healthy food in quantity to promote the population food sovereignty, which must be supported by biotechnology.

Keywords: Socio-environmental Law; Biodiversity; Socio-environmental Conflicts; Creole Seeds; Traditional Farmer.

\section{INTRODUÇÃO}

A conservação da biodiversidade consiste em uma das mais importantes questões ambientais do século XXI. Há um potente conflito entre o desenvolvimento da biotecnologia, a reprodução do capital ambiental e a preservação da vida planetária. Diante da tendência do capital biotecnológico de se desenvolver imoderadamente surge o conflito: o capital biotecnológico, composto por cientistas e empresas, empenha-se em desenvolver novas cultivares com melhores rendimentos, em substituição às variabilidades genéticas crioulas, consideradas de baixo rendimento. Os novos produtos, ao contrário dos crioulos devem ser geneticamente uniformes. Por razões de reprodução e crescimento do capital, a engenharia genética deve criar sempre novas cultivares, a fim de manter suas sementes como mercadorias viáveis. Isto, paradoxalmente dependente da disponibilidade de material com diversidade genética, mas a prática tende a destruir esta variabilidade, devido ao seu desenvolvimento mercadológico baseado em sementes geneticamente modificadas e na monocultura. Quer dizer, a biotecnologia promove a erosão da diversidade genética que precisa para dar continuidade a seus métodos.

Neste dilema, o direito legitima, por um lado, a apropriação privada da biodiversidade por meio do regime de patentes, da propriedade intelectual de cultivares e sementes e de repartição de benefícios, e por outro, protege a biodiversidade pelo princípio do meio ambiente ecologicamente equilibrado para as presentes e futuras gerações (Constituição Federal de 1988) e mediante a conservação da diversidade biológica por estratégias de conservação in situ e ex situ, expressas no ordenamento infraconstitucional pela Lei n. 13.123 e pela Convenção de Diversidade Biológica. Trata-se de um conflito entre o direito coletivo, o meio ambiente, os direitos individuais e a propriedade privada.

Esse fenômeno revela contradição do Direito do século XXI, que tem que manter a regulamentação da propriedade e da mercadoria ao mesmo tempo em que introduz as lutas sociais pela conservação da diversidade da vida. Isto é, o direito não se desenvolve em apenas um sentido, mas em um fenômeno complexo, que se expressa na realidade enquanto síntese de múltiplas determinações, o que decorre de sua existência enquanto fenômeno social e concreto.

Diante destes pressupostos, o artigo está dividido em quatro partes. Na primeira, analisa os aspectos sócio-jurídicos da biodiversidade; na segunda, aborda as formas de conservação da biodi- 
versidade in situ e ex situ, tratando como esta última relaciona-se com a industrialização do campo; na terceira parte estuda como estas escolhas jurídicas e políticas vêm legitimando a transformação da natureza em mercadoria; e, por fim, busca demonstrar a importância dos camponeses do MST para a conservação da biodiversidade em seu habitat natural.

\section{BIODIVERSIDADE E ASPECTOS SOCIOJURÍDICOS}

Desde sempre o ser humano atua em seu meio ambiente natural mediado por leis naturais e normas institucionalizadoras, em condição natural de interação metabólica essencial à vida (FOSTER, 2014, p. 274 e MARX, 2011, p. 120). Neste processo, a percepção e curiosidade sobre a diversidade de vidas na natureza foi primordial para a integração do ser humano em seu território. Na modernidade, porém, houve um afastamento das leis naturais na crença da possibilidade da substituição e "melhoramento" da natureza. Este processo histórico fez com que a diversidade da vida fosse estudada pelas lentes das ciências naturais, enquanto unidades da vida biológica.

Nos primórdios dos estudos na modernidade sobre ciências naturais a diversidade da vida era vista como algo constante. Apenas a partir dos anos 1960, como decorrência da industrialização e dos consequentes impactos da ação humana sobre o mundo natural, a diversidade passou a ser vista como uma riqueza inestimável, a qual deve ser conservada, visto que sua perda e erosão atrelam-se a uma crise global de extinção da vida.

Diante disso, mais tarde nos anos 1980 o conceito de "diversidade biológica", que assumiu centralidade, permitiu reconhecer o crescente impacto das ações humanas sobre os sistemas biológicos planetários, bem como que a perda da diversidade biológica constitui uma das questões contemporâneas mais fundamentais (FRANCO, 2013, p. 03).

Em 1982, o conservacionista Ernst Mayr publicou o livro $O$ desenvolvimento do pensamento biológico: diversidade, evolução e herança no qual sustentou que todo processo biológico implica a biodiversidade, que constitui um dos aspectos mais fundamentais da vida (MAYR, 1998, p. 161).

O conceito de "biodiversidade" surgiu em 1988 como contração de "diversidade biológica", na obra do biólogo Edward O. Wilson, que tratou essencialmente da perda da diversidade biológica e possíveis remediações. Os estudos da natureza abandonaram gradativamente a ideia de preservação natural, mediante uma visão romântica de paisagens sublimes e intocadas, em direção à conservação da biodiversidade, com base na ideia do papel fundamental do processo evolutivo no surgimento de espécies e da vida terrestre, com base na teoria sintetizada por Charles Darwin (FRANCO, 2013, p. 04-05).

Com base neste desenvolvimento ocorrido nos estudos da natureza, a biodiversidade passou a ser um termo recorrente, porém, conforme elucida Antônio Carlos Diegues, em um primeiro momento foi restrito à ideia de processo natural, ignorando a intervenção humana (DIEGUES, 2016, p. 03).

Por muito tempo foi exaltada a estratégia de conservação por meio da criação de áreas protegidas com restrição ao avanço humano, tais como reservas e parques, enquanto principal método de preservação da diversidade. Tais modelos foram objeto de críticas, visto que nos diversos países em que foram aplicados entraram em crise, porque não conseguiram conter a erosão das espécies, nem mesmo as que mantinham dentro dos parques, especialmente animais e plantas de maior por- 
te. Face a esta situação, vislumbrou-se que a biodiversidade também consiste em produto da ação de sociedades humanas, especialmente, sociedades tradicionais não-industriais, que com modo de vida e cultura atrelados à natureza, favorecem a vida de diversas espécies animais e vegetais com base em valores socialmente reproduzidos (DIEGUES, 2016, p. 04).

Por meio dos assentamentos humanos, principalmente, deu-se um encadeamento complexo ocorrido em centenas de anos de mudanças materiais, sociais e culturais, em diversos povoamentos locais do mundo, pelas quais a variabilidade de seres-vivos restou impactada (MAZOYER e ROUDART, 2010, p.90-101).

Esta percepção sobre a interação dialética entre ser humano e meio ambiente acentua a relevância dos agroecossistemas para a biodiversidade, pois a natureza é fortemente impactada pela agricultura e pela criação de animais ligados aos assentamentos. Nesse sentido, Juliana Santilli explicou que aproximadamente a partir 1995 o conceito de agrobiodiversidade começa a ser elaborado, pelo esforço entre diversas áreas do conhecimento. Nas palavras da autora, a agrobiodiversidade (SANTILLI, 2009, p. 91):

\footnotetext{
Reflete as dinâmicas e complexas relações entre as sociedades humanas, as plantas cultivadas e os ambientes em que convivem, repercutindo sobre as políticas de conservação dos ecossistemas cultivados, de promoção da segurança alimentar e nutricional das populações humanas, de inclusão social e de desenvolvimento local sustentável.
}

Segundo a autora, a agrobiodiversidade engloba espaços cultivados, espécies direta ou indiretamente manejadas e a diversidade genética a eles associadas, tratando-se, portanto, de um conceito amplo, atrelado à variabilidade de ecossistemas, da fauna, de insetos, bem como a diversidade subterrânea e microbiana (SANTILLI, 2009, p. 93).

Pelo conceito de agrobiodiversidade, nota-se que o aspecto social faz parte da biodiversidade, visto que o ser humano depende de espécies animais e vegetais para sua reprodução social, o que se revela pela domesticação. Isso demonstra que a diversidade é inerente à história humana (DIEGUES, 2016, p. 09).

A intervenção social sobre a diversidade biológica foi valiosa ao menos desde o surgimento da agricultura há mais de 10 mil anos devido a diversos aspectos, como sacralidade, espiritualidade, ancestralidade, alimentação e as mais diversas dimensões da vida, todas dimensões altamente influenciadas pela natureza em que a sociedade vivia. Assim, do mesmo modo que as sociedades humanas sofreram diretamente a influência da natureza em que viviam, tendo a diversidade biológica, portanto, muita importância para as sociedades, num processo de interação, a biodiversidade também sofreu mudanças. A sociedade moderna, porém, restringiu o valor da biodiversidade que passou a ser vista apenas: "enquanto objeto de pesquisa, fonte de impulsos tecnológicos nas biociências e nas bioindústrias, transformados em vetores de concentração econômica através de patentes." (MATHIAS et al. 2006, p. 13). Apesar de curto, este momento histórico tem sido altamente devastador e com potencial de destruição total da biodiversidade.

Entretanto, como o conceito de biodiversidade surge no contexto da ciência eurocêntrica moderna, também a sua proteção jurídica atrela-se ao paradigma de natureza afastada do ser humano. Nesse contexto, as discussões internacionais ao redor da biodiversidade demonstram a existência de duas principais vertentes presentes na preocupação com a conservação do meio ambiente no final do século XX, cada uma delas abarcando diversas correntes. 
Uma dessas vertentes é chamada "conservacionista/preservacionista" que mantém o paradigma moderno da separação entre natureza e ser humano e defende que a proteção da natureza só pode ocorrer pelo afastamento de qualquer interferência humana, pautado em uma visão romântica, estética e unidisciplinar de natureza, decorrente do naturalismo do século XIX. Esta vertente tende a excluir o ser humano, qualquer ser humano e qualquer sociedade humana, da convivência com a natureza pura, intocada. É claro que em perspectiva radical esta vertente separa o mundo humano do mundo natural, entendendo que o mundo humano é a superação da natureza. Em outras palavras, que a humanidade prescinde da natureza, podendo substituí-la por sua técnica e engenho. Para o bem da natureza, esta corrente propõe a criação de espaços naturais protegidos longe do mundo humano, estabelecendo uma dicotomia entre os espaços protegidos e os espaços humanos nos quais a natureza poderia deixar de existir.

A outra vertente sobre a natureza considera a indispensabilidade da relação sociedade/natureza, abarcando duas correntes: o "ambientalismo moderado ou "sustentabilidade débil", que a partir do olhar antropocentrista preceitua que a natureza é simples repositório de recursos, os quais devem servir principalmente à existência humana, com base na economia ambiental (FOLADORI e PIERRI, 2005, p. 68-73); bem como a corrente "humanista crítica" (FOLADORI e PIERRI, 2005, p. 73-80), também chamada de "ecologia social" que se pauta pela relação entre sociedade e natureza, ressaltando que a paisagem é uma estrutura espacial resultado de processos naturais e atividades humanas e que a natureza e o ser humano estão constantemente se transformando, o que rompe com a ideia de natureza intocada e de "bom selvagem" (DIEGUES, p. 06-08).

Sobre esta última corrente, esclarece Diegues (p. 09):

os que se baseiam na ecologia social têm proposto que a biodiversidade não é um conceito simplesmente biológico, relativo à diversidade genética de indivíduos de espécies, e de ecossistemas, mas é também resultado de práticas, muitas vezes milenares, das comunidades tradicionais que domesticam espécies, mantendo e, em alguns casos, aumentado a diversidade local.

A vertente conservacionista/preservacionista de natureza enfatiza as áreas protegidas chamada de uso indireto, tais como parques nacionais e reservas biológicas, nas quais não é admitida a moradia humana, com base na ideia de que a biodiversidade seria um produto apenas natural e que sua proteção pressuporia a ausência de pessoas em seu interior. Esta visão consistiu no padrão inicial de preocupação com a natureza, expressa, por exemplo, pela teoria da ecologia profunda (FOLADORI e PIERRI, 2005, p. 94-96) e pelo direito desde as primeiras regulações do meio ambiente, que partem do conceito de "propriedade", da separação entre ser humano e natureza e da proteção da natureza contra o ser humano, em latente manejo da tendência destrutiva do capital.

Neste contexto, tendo em vista que a natureza significa em essência um pressuposto primordial para produção de riquezas, foi tensionada a compatibilização entre sua conservação e sua exploração econômica, considerando a lógica de produção de mercadoria que predomina no sistema de produção globalizado. Por isso, desde os primeiros documentos internacionais de proteção ambiental é expresso este latente antagonismo entre economia capitalista e proteção da natureza, expressa em especial na Conferência de Estocolomo de 1972.

Tais discussões atrelam-se à segunda vertente acima referida, a social, que defende a importância da atuação humana na proteção da natureza, porém, mediante duas estratégias diame- 
tralmente opostas: estratégias de economia verde que "corrigem" problemas ambientais mediante estratégias de mercado e, por outro lado, estratégias humanistas, que concentram esforços em estratégias não capitalistas de proteção da natureza, caracterizados numa perspectiva socioambiental.

Diante disso, desenvolveu-se no âmbito jurídico internacional a discussão sobre o conceito de “desenvolvimento sustentável”, materializada no Relatório de Brundtland em 1987 (FOLADORI, 2005, p. 28-43) e expressa em diversos sistemas nacionais de direito ambiental. No Brasil está presente em alguns artigos da Constituição Federal de 1988, como o art. 225 cuja essência é a proteção da biodiversidade e que dispõe sobre o princípio da proteção do meio ambiente ecologicamente equilibrado para as presentes e futuras gerações. Outro exemplo importante é a proteção da função socioambiental da terra, tanto rural quanto urbana, expressa nos arts. $5^{\circ}$, XXIII, art. 170, III, 182, 184, 185 e 186.

No mencionado artigo 225, consta expressamente a preocupação com a perda da variabilidade genética e necessidade de fiscalização de entidades dedicadas à pesquisa e manipulação genética, o que decorreu do intenso avanço, naquele período, de empresas de biotecnologia agrícola sobre a agricultura brasileira.

Ainda no contexto de discussões sobre humanismo e natureza, em 1992 ocorreu a Conferência das Nações Unidas sobre o Meio Ambiente e Desenvolvimento (ou Rio-92). A partir do aparente dilema entre proteção do meio ambiente e desenvolvimento econômico (especialmente em países periféricos) a discussão se centrou no conceito de desenvolvimento sustentável, mediante a criação de compromissos juridicamente vinculantes aos governos pela aprovação de cinco documentos, entre eles a Convenção sobre Diversidade Biológica (CDB). O aspecto mais discutido no âmbito desta convenção foi a propriedade intelectual dos recursos genéticos e o da distribuição de benefícios (INOUE, 2003, p. 50-55).

A CDB é um marco na normativa internacional e inclui três objetivos: a conservação da diversidade biológica; a utilização sustentável de seus componentes e a repartição justa e equitativa dos benefícios derivados da utilização dos recursos genéticos. Portanto, engloba o tema da soberania dos países e o papel dos povos indígenas e tradicionais para a diversidade biológica, trazendo, assim, a discussão da importância da relação entre sociedade e natureza. No Brasil, vigora desde 1993 como Convenção-Quadro, tendo sido aprovada em 1994 e promulgada em 1998, pelo Decreto n. 2.519/1998.

Nas discussões ao redor da CDB, os países centrais defendiam a ideia de diversidade biológica como um "patrimônio comum da humanidade", enquanto os outros, historicamente prejudicados pela extração de recursos naturais, defendiam seus direitos soberanos mediante patentes (INOUE, 2003, p. 37). No documento aprovado foi vencedora a das soberanias nacionais sobre a biodiversidade.

Representações principalmente da África, registraram a inadequação da proteção dos direitos das populações tradicionais, da não aplicação retroativa aos recursos já extraídos e da vulnerabilidade quanto à OMC (INOUE, 2003, p. 142-143).

A finalidade da Convenção, segundo seu artigo $1^{\circ}$, é regular tanto o uso sustentável da biodiversidade, quanto da retribuição econômica aos países de origem, a fim de investir na conservação. Entretanto, o documento foi vago quanto à repartição dos benefícios a estes países. 
A CDB trata da repartição de benefícios, mas o faz junto com o reconhecimento de patentes, de forma a restringir a biodiversidade ao interesse econômico e mercadológico. Portanto, ainda que a CDB tenha possibilitado o debate sobre a importância da biodiversidade para a vida planetária e tenha tangenciado a necessidade de proteção dos conhecimentos tradicionais de comunidades tradicionais e povos indígenas associados à biodiversidade, criou a abstração jurídica da "propriedade da natureza", especialmente sobre os chamados recursos genéticos, os conhecimentos tradicionais e as espécies de interesse comercial.

Durante as discussões da CDB alguns países em desenvolvimento, principalmente os latino-americanos e o grupo dos países megadiversos, defenderam pautas com base em uma lógica monetária ao redor da biodiversidade, voltada apenas à maior participação no valor gerado pelos produtos decorrentes da apropriação privada da biodiversidade (MATHIAS et al. 2006, p. 14).

Por tudo isso, ao mesmo tempo que a $\mathrm{CDB}$ representou relevante avanço na proteção de conhecimentos e da biodiversidade, também protegeu interesses comerciais dos países ricos, garantidos pelo uso de soluções de mercado e pela ausência de retroatividade. A universalização dos recursos genéticos possibilitou transações mediante direitos de propriedade intelectual pelo sistema de patentes, compatível com o acordo jurídico do TRIPs (Trade-Related Aspects of Intellectual Property Rights), que criou padrões mínimos para proteção destes direitos e que foi um Acordos que embasaram a criação da Organização Mundial do Comércio. Isto significou, na realidade, uma garantia aos negócios sobre a biodiversidade muita acima de sua proteção efetiva, porque TRIPS é fundamentalmente um tratado de interesses econômicos. Por outro lado, a ausência de reconhecimento pela responsabilidade retroativa deixou os países que já foram devastados em sua biodiversidade sem qualquer recompensa ou possibilidade de restauro.

A CDB tornou bens jurídicos as mais diversas abstrações, como os chamados "componentes da diversidade biológica" e regulamentou práticas de conservação (in situ e ex situ) da biodiversidade, abrindo as portas de acesso às empresas de tecnologia aos recursos da biodiversidade, possibilitando mecanismos de repartição de benefícios que permitiram a uniformização das legislações nacionais e a consequente segurança jurídica das entidades de biotecnologia em seu avanço sobre a natureza. Esse movimento é expresso, no Brasil, pelas Leis de biossegurança (Lei 8.974/1995, Lei 11.105/2005) e pela Lei que dispõe sobre o Sistema Nacional de Sementes e Mudas (Lei n. 10.711/2003).

Devido à reconhecida fragilidade das disposições sobre a repartição de benefícios na CDB, as Conferências das Partes (COPs) posteriores, especialmente a partir da COP-7, retiraram a discussão da temática, especialmente em relação ao uso dos conhecimentos tradicionais associados, mas também em relação ao uso da biodiversidade dos países originários, tendo em vista a aprovação, em 1992, da soberania nacional sobre estes recursos. Finalmente, em 2014 foi estabelecido o Protocolo de Nagoya que trata das obrigações dos países usuários de bens do patrimônio genético para com os países de origem, sempre levando em conta a não retroatividade, isto é, as obrigações sobre o uso destes bens somente se referem às novas utilizações de recursos genéticos. O temor da retroatividade era a responsabilização e pagamento de benefícios pelo uso da batata ou do milho americano e da soja chinesa.

As reuniões das Conferências da Partes posteriores à CDB, e especialmente o Protocolo de Nagoya em 2014, influenciaram a produção legislativa de Estados nacionais. No Brasil, a Lei n. 
13.123/2015 e o Decreto n. 8.722/2016, que regulamentam o uso da biodiversidade e dos conhecimentos tradicionais a ela associados, foram promulgados.

\section{CONSERVAÇÃO DE RECURSOS GENÉTICOS IN SITU E EX SITU}

No final da década de 1960 iniciavam-se os debates acerca dos efeitos do desenvolvimento industrial sobre a natureza, já estava presente na sociedade civil a necessidade de mudança na ação humana sobre a natureza. Pairava no âmbito internacional uma grande preocupação com a forma de conservação dos recursos e com o apoio da Organização das Nações Unidas para a Alimentação e a Agricultura (FAO) e, no Brasil, com a constituição da Empresa Brasileira de Pesquisa Agropecuária (Embrapa), a decisão tomada foi no sentido de dar preferência pela conservação ex situ, fora do habitat natural e em ambientes controlados, como a medida científica mais segura para a conservação da diversidade biológica (SANTONIERI; BUSTAMANTE, 2016, p. 678). Respondendo, portanto, à discussão da perversa ação humana sobre a natureza e a biodiversidade, a solução proposta e levada à prática foi a preservação de genes ex situ. Permitindo, então, a continuidade da devastação fora dos ambientes tecnicamente protegidos.

Foi neste contexto que em 1972 foi realizada a Conferência das Nações Unidas sobre o Meio Ambiente Humano em Estocolmo, na qual prevaleceu uma visão conservacionista, que optava por proteger a natureza em espaços sacralizados e separados da humanidade. Esta concepção de espaços protegidos se bem analisada significava a extensão da conservação ex situ para espaços mais amplos e naturalmente protegidos. É claro que a conservação ex situ não permite a proteção e conservação de toda biodiversidade, mas apenas daqueles seres, animais e plantas aos quais se projeta utilidade futura.

A proteção ex situ é necessariamente cara e limitada, pois para proteger toda a biodiversidade longe da ação humana se fazia necessário criar espaços maiores, onde a natureza pudesse viver longe das mãos predatórias. Claro que esta visão esquecia ou omitia que muitas mãos humanas não são predatórias, mas auxiliares na proteção da biodiversidade. A ideia do capitalismo do século $\mathrm{XX}$, portanto, foi de que a proteção da natureza só pode se fazer separada da humanidade, porque acreditava numa dicotomia absoluta entre a produção agrícola e a manutenção da biodiversidade, entendendo que para produzir é necessário eliminar tudo o que não seja a própria produção. Os seres vivos que não fizessem parte daquela produção teriam que estar fora do território, não compreendendo que há povos e gentes que são capazes de compartilhar sua produção com todos os demais seres vivos da natureza. É nesse sentido que as reservas e parques não poderiam ter em seu interior nem mesmo povos indígenas e outros tradicionais que se mantêm em interação com o território em que vivem, e, que ao contrário, auxiliam o aumento e desenvolvimento da biodiversidade não humana. Esta ideia esconde um evolucionismo social que imagina que todos os povos 'evoluirão' para uma sociedade predatória do ambiente.

A partir da visão de natureza intocada prevalente na ideia conservacionista/preservacionista do meio ambiente, a proteção de recursos genéticos foi, portanto, inicialmente pensada em estratégias artificiais afastadas da interação humana. Por isso, a proposta de isolamento dos recursos genéticos e a guarda e proteção em locais tecnicamente neutros, mantendo sua conservação ex situ. Assim guardados e conservados, os recursos genéticos poderiam sofrer alterações da natureza e 
até mesmo a sua extinção porque estavam fora de seu habitat, apenas como uma reserva de futuro. Demorou muito para que parte da ciência entendesse que os recursos genéticos fazem parte do ecossistema natural e cultural, na maior parte das vezes associados aos povos e às comunidades humanas. As discussões sobre a crescente perda de recursos genéticos cresceu na sociedade civil e científica internacional e nos anos que se seguiram à Conferência de Estocolmo assumiram centralidade nos debates ambientalistas e socioambientalistas. Diante disso, um dos principais enfoques dados pela Conferência das Nações Unidas sobre Meio Ambiente e Desenvolvimento, em 1992, consistiu na proteção e guarda da diversidade biológica, do que decorreu a aprovação do texto da CDB.

A CDB, então, estabeleceu duas estratégias de proteção da biodiversidade, mediante duas formas de conservação, uma mantida como "ex situ", manutenção de genes ou conjunto de genes em condições artificiais, e outra, "in situ”, com as espécies vivendo em seu habitat natural, muito mais efetiva e abrangente, porque pode proteger todas as espécies ao mesmo tempo. Entre os meios de proteção in situ está o incentivo a que os povos tradicionais mantenham e desenvolvam sua cultura de uso compartido da natureza estabelecido no artigo 8, j, da Convenção.

Sobre as estratégias ex situ de conservação, João Rodrigues de Paiva, agrônomo da EMBRAPA, doutor em melhoramento genético vegetal e pesquisador, explica que as diversas instituições concluíram que há limitações da conservação da variabilidade genética de espécies através de coleções e bancos de germoplasma (ex situ):

\footnotetext{
Afora os problemas de natureza não técnica que, muitas vezes, provocam solução de continuidade no sistema de conservação, os problemas de ordem técnica são limitantes para certas culturas e de solução onerosa para muitas, devido ao desequilíbrio biológico provocado pelo monocultivo. (PAIVA, 1994, p. 66)
}

Estudos apresentados por Santonieri e Bustamante (2016, p. 682) demonstraram, igualmente, que a conservação ex situ mostrou-se insuficiente, uma vez que as espécies vegetais que foram mantidas fora de seu habitat natural apresentaram maiores dificuldades de se adaptarem novamente ao ambiente no momento de reintrodução natural. Diante dessas dificuldades práticas, e reconhecendo a importância dos povos e agricultores tradicionais para a conservação da biodiversidade, a CDB em seu artigo $8^{\circ}$ definiu as obrigações dos países signatários para a conservação in situ. Em seu artigo $9^{\circ}$ estipulou que a conservação ex situ será feita na medida do possível e com a finalidade de complementar a conservação in situ, o que significa um reconhecimento da importância da natureza e de seu trabalho e criação na preservação dos ambientes e, principalmente, da alimentação humana.

Na conservação ex situ é dispensado o trabalho da natureza. Na conservação in situ ou on farm é mantido o conhecimento tradicional dos povos e agricultores, a troca e o contato direto com o trabalho da natureza. Sobre o assunto, Santonieri e Bustamante elucidam que: "nas duas últimas décadas, [há] um processo de reconhecimento cada vez maior do papel dos agricultores, não só no interior do programa de conservação dos recursos genéticos, mas também como atores fundamentais na produção de conhecimentos sobre a agrobiodiversidade." (2016, p. 684).

Não poderia ser muito diferente a posição de uma Convenção Internacional para a preservação da Diversidade Biológica ao privilegiar a conservação in situ, que não apenas tecnicamente 
protege toda a biodiversidade. Deve ficar claro que a ideia de preservar a biodiversidade em locais imunes a ação humana, mesmo de povos tradicionais, se equipara à preservação ex situ porque artificializa a relação da natureza com a cultura. Por isso, o documento internacional sedimenta o entendimento de que a conservação de materiais oriundos de recursos da biodiversidade é insuficiente, sendo necessário, para além disso, reconhecer o papel do conhecimento dos povos e dos agricultores tradicionais para a conservação e expansão da biodiversidade.

Muitas formulações presentes na CDB que representam um avanço na proteção da biodiversidade, porém, contém grandes limitações porque reduzem a natureza a seu valor mercadológico, na medida em que não apresentam mecanismos concretizadores de outras estratégias sobre a natureza, tampouco da proteção dos conhecimentos tradicionais associados à biodiversidade.

\section{A LEGITIMAÇÃO POLÍTICA E JURÍDICA DA MERCANTILIZAÇÃO DA NA- TUREZA E APROPRIAÇÃO DOS CONHECIMENTOS TRADICIONAIS}

Na década de 1960, ao lado da preponderância das estratégias de conservação ex situ para conservação da biodiversidade ganhou força um modelo específico de produção, comércio e expansão agrícola conhecido como "Revolução Verde". Tal paradigma foi responsável pela expansão das fronteiras agrícolas que caminhou ao lado da proposta de industrialização do campo mediante os pacotes financiados e subsidiados de insumos agrícolas e maquinários voltados à produção de monoculturas.

Desta forma era possível desmatar, envenenar, desconsiderar o conhecimento tradicional dos camponeses ao classificá-lo como método arcaico e ineficaz de produção e conservação da biodiversidade. Isto parecia positivo porque a conservação da biodiversidade era feita ex situ; dispensando os habitats naturais, com a formação de bancos de germoplasma e laboratórios, tudo controlado pela ciência. Significava passe livre para destruir a natureza e expandir as fronteiras agrícolas, já que a natureza e suas sementes e cultivares estavam "enjauladas" nos bancos de germoplasma.

Assim, com um complexo processo viabilizado pelo conjunto de mudanças tecnológicas ocorridas no campo mediante a Revolução Verde, foi possível acentuar a concentração da propriedade da terra ao mesmo tempo em que se criavam novas formas de transformação da natureza em mercadoria, o que ocorreu ao se incorporar as sementes e cultivares por meio da propriedade intelectual ao projeto de expansão do capital.

Desta forma, expressão do método de conservação ex situ da biodiversidade foi forjada pelo setor empresarial rural como saída para contenção da erosão genética. Sobre o assunto elucida Juliana Santilli (2009, p. 226) que:

Os bancos de germoplasma atendiam às necessidades dos setores formais, e os centros internacionais de pesquisa agrícola se voltavam especialmente para o desenvolvimento de variedades de alto rendimento, dependentes de insumos externos caros, aos quais os agricultores pobres não tinham acesso, $\mathrm{e}$ as variedades localmente adaptadas não recebiam a mesma atenção. Assim, a conservação ex situ passou a ser cada vez mais associada à revolução verde. Além disso, os agricultores sempre tiveram pouco acesso aos recursos fitogenéticos conservados em bancos de germoplasma. 
É possível afirmar que as estratégias ex situ de conservação da biodiversidade não propiciaram acessibilidade aos agricultores. Somadas ao arcabouço legislativo constituído nesse contexto voltaram-se primordialmente a garantir que, cada vez mais, as sementes e a biodiversidade destinadas à alimentação humana fossem propriedades das grandes empresas multinacionais sementeiras.

Nesse contexto, o agricultor que tradicionalmente produzia, multiplicava e trocava com outros agricultores suas sementes, passou a ter que pagar por um pacote de sementes, fertilizantes e agrotóxicos para as indústrias do agronegócio e bancos de germoplasma, porque suas sementes passaram a ser proibidas de uso e comercialização.

Percebe-se que os direitos de propriedade sobre sementes e cultivares atrelaram-se a movimentos econômicos próprios do capital rural biotecnológico, expresso pela busca de novas formas de aumentar e valorizar as possibilidades de acumulação. Neste sentido, se confirmaram as afirmações feitas por Karl Marx, no século XIX, ao explicar a acumulação primária enquanto um pressuposto da expansão do capital e o papel das leis em garantir tal acumulação:

O progresso do século XVIII consiste em ter tornado a própria lei o veículo do roubo das
terras permanentes ao povo, embora os grandes arrendatários empregassem simultânea
e independentemente seus pequenos métodos particulares. O roubo assume a forma
parlamentar que lhe dão as leis relativas ao cercamento das terras comuns, ou melhor, os
decretos com que os senhores das terras se presenteiam com os bens que pertencem ao
povo, tornando-os sua propriedade particular, decretos de expropriação do povo. (MARX,
2017 , p. 846)

Assim como os processos de acumulação do século XVIII foram legitimados e impulsionados pela lei, também no final do século XX e início do século XXI, são as leis que legitimam o mesmo processo de usurpação da natureza. Primeiro o direito transformou a terra em propriedade, depois, aplicando a mesma abstração da propriedade privada, passou a considerar tudo como mercadoria. Assim ocorreu, por exemplo, com as sementes, com a água e recentemente isso ocorre com os conhecimentos tradicionais associados à biodiversidade, transformados em propriedade imaterial.

Exemplo disso é possível ser observado na Lei n. 13.123 de 2015 que demonstra como o direito expressa a crescente tendência de usurpação privada da natureza. Tal lei regulamentou a CDB no Brasil e trata do acesso ao patrimônio genético, da proteção e do acesso ao conhecimento tradicional associado e sobre a repartição de benefícios para conservação e uso sustentável da biodiversidade, revogando a Medida Provisória n. 2.186/2001 (MOREIRA et al. 2017).

A Lei n. 13.123 de 2015 também definiu o conceito de condições in situ de conservação da biodiversidade como aquelas "condições em que o patrimônio genético existe em ecossistemas e habitats naturais e, no caso de espécies domesticadas ou cultivadas, nos meios onde naturalmente tenham desenvolvido suas características distintivas próprias, incluindo as que formem populações espontâneas" (art. $\left.2^{\circ}, \mathrm{XXV}\right)$. Como condições ex situ conceituou as "condições em que o patrimônio genético é mantido fora de seu habitat natural" (art. $2^{\circ}$, XXVII).

Mais precisamente, é no artigo $2^{\circ}$, inciso III, que a Lei n. 13.123 de 2015 viola os direitos coletivos. Assim dispõe a lei no artigo $2^{\circ}$, inciso III - "conhecimento tradicional associado de origem não identificável - conhecimento tradicional associado em que não há a possibilidade de vincular a sua origem a, pelo menos, uma população indígena, comunidade tradicional ou agricultor tradicional". Embora a motivação da edição da referida lei tenha sido justificada pela necessidade de prote- 
ger e reconhecer o conhecimento dos povos tradicionais e dos agricultores tradicionais, a sociedade civil e a doutrina especializada vêm apresentando diversas críticas (MOREIRA et al. 2017).

A Lei n. 13.123 de 2015 desrespeita o conhecimento coletivo dos povos tradicionais e dos agricultores tradicionais, entre os quais a própria lei inclui o agricultor familiar, conforme o inciso XXXI, do artigo $2^{\circ}$, ao tratar do conhecimento não identificável como forma de individualizar direitos coletivos, justamente por existirem direitos que pertencem a muitos povos, tornando-se difícil identificar de qual povo surgiu o conhecimento, uma vez que este conhecimento é coletivo, isto é, de muitos e não de um só. Em contrassenso, a lei permite a apropriação desses conhecimentos sem a repartição de benefícios com os povos e agricultores tradicionais quando no artigo $9^{\circ}, \S 2^{\circ}$, dispõe que "o acesso a conhecimento tradicional associado de origem não identificável independe de consentimento prévio informado." Neste sentido:

Alei n. 13.123/15, embora anuncie que protege os conhecimentos tradicionais associados ao patrimônio genético de populações indígenas, de comunidade tradicional ou de agricultor tradicional, o que, na realidade, faz, é permitir e organizar a exploração econômica do patrimônio genético nacional e dos conhecimentos tradicionais a eles associados. Neste sentido, contorna as naturais dificuldades existentes para essa exploração que, de um lado, encontra o interesse econômico, e, de outro, o interesse de todos os direitos das populações tradicionais. Exatamente porque é enorme a contradição entre estes polos e maior ainda a dificuldade de contorná-las, a Lei não hesita em violar as demais Leis do Estado e as Normas Internacionais que o Brasil reconheceu e internalizou, alem de evitar avançar e aprofundar questões como a origem, o território e a consulta prévia. A Lei viola a Constituição, viola as Convenções e fere os Tratados sobre os direitos dos povos. (SOUZA FILHO, 2017, p. 122)

Ainda no sentido da usurpação da natureza e do conhecimento tradicional associado à biodiversidade, outras legislações devem ser objeto de críticas, como, por exemplo, a Lei n. 10.711 de 2003, que dispõe sobre o Sistema Nacional de Sementes e Mudas, uma vez que impõe um sistema formal que só as empresas sementeiras conseguem cumprir. Segundo Juliana Santilli (2009, p. 154):

O impacto sobre a agrobiodiversidade é perverso: deixam de ser produzidas (e, consequentemente, utilizadas) sementes de variedades adaptadas a condições socioambientais específicas e passam a ser produzidas apenas as variedades comerciais, vendidas em larga escala, cujos custos para a manutenção da estrutura técnica exigida pela lei são compensados com as vendas em grandes quantidades.

Para a autora, a Lei de Sementes e Mudas impõe excessivas restrições/limitações para que os agricultores possam produzir suas próprias sementes, desconsiderando o fato de que essas sementes são, em geral, as mais adaptadas às condições locais. (SANTILLI, 2009, p. 147-148).

Demonstrando a continuidade deste movimento expresso pelo direito, tramitam no Brasil diversos Projetos de Leis, que se coadunam com a tendência de crescente apropriação privada da natureza, especialmente da sua biodiversidade e dos conhecimentos tradicionais associados. Um dos exemplos é o Projeto de Lei (PL) 827 de 2015 de autoria do ex-deputado ruralista Dilceu Sperafico (PP-PR) e que tem como proposta a alteração da Lei de Proteção de Cultivares Lei n. 9.456 de 1997, que já é bastante restritiva aos direitos socioambientais dos agricultores. Esta lei regulamenta a propriedade intelectual referente às cultivares que são plantas que tiveram alguma modificação pela ação humana. A proposta deste PL é de condicionar a comercialização do produto que for ob- 
tido na colheita a uma autorização do detentor (que geralmente são as indústrias sementeiras) das cultivares e, também, tem o objetivo de aumentar o número de cultivares protegidas, para restringir o acesso e a utilização livremente pelos agricultores, tornando propriedade privada o que antes era de acesso comum dos agricultores e povos tradicionais.

Assim, um modelo excludente da natureza, dos povos indígenas e tradicionais e dos agricultores foi construído a partir da modernidade capitalista. Por outro lado, os camponeses, indígenas e não indígenas, continuaram em resistência às formas de acumulação primitiva e capitalista. Os camponeses sempre se puseram em resistência à acumulação primitiva que trouxe a grande revolução agrária no campo, ao fazer a transição do feudalismo para o capitalismo, a partir dos cercamentos e aumento da produtividade, que levou à constituição da propriedade privada. Neste sentido, ver: WOOD, 2000 e SCOTT, 2011.

\section{RESISTÊNCIA CAMPONESA À MERCANTILIZAÇÃO DA NATUREZA: OS BANCOS DE SEMENTES E AS JORNADAS DE AGROECOLOGIA DO MST NO ESTADO DO PARANÁ}

Com uma trajetória de resistência marcante no Brasil o Movimento dos Trabalhadores Rurais Sem Terra (MST) é uma organização iniciada na década de 1980, em decorrência da marginalização e exclusão dos trabalhadores rurais das terras.

Durante esses 35 anos de caminhada e luta pela sobrevivência e pelo acesso à terra, o MST foi percebendo que o que estava em disputa era muito mais do que o acesso à terra. Para a manutenção da cultura camponesa e manutenção da própria terra nas mãos das famílias era preciso pensar em outra forma de produção sem a dependência das indústrias agroalimentares e buscando alternativas para alcançar a soberania alimentar dos coletivos, das famílias, dos acampamentos e assentamentos, nascendo, assim, experiências de agroecologia.

Era preciso produzir alimentos e proteger a natureza para produzi-los. A agricultura convencional ou industrial, baseada no uso intensivo de agrotóxicos e de monocultura extensiva, só é viável em grandes extensões de terra, por isso, se o pequeno agricultor produz desta forma acaba por se destruir como projeto e faz voltar a concentração fundiária com o empobrecimento ou a expulsão da maioria dos agricultores da terra. Para a pequena agricultura familiar a alternativa acaba sendo um modelo que interage e protege a natureza e mantém a biodiversidade como fundamento da produção.

A alternativa agroecológica exige a existência, permanência e conservação das sementes crioulas e do conhecimento tradicional nas mãos dos camponeses e dos povos tradicionais, porque as sementes e a biodiversidade devem permanecer em harmonia e interação. Desta forma, a partir de práticas que expressam resistência contra a crescente mercantilização da natureza, agricultores perpetuam bancos de sementes crioulas com tecnologias simples de conservação, uso de garrafas pets e potes de vidro, trocas de receitas de caldas para substituir os fertilizantes químicos, trocas de conhecimentos para determinarem qual espécie vegetal serve para a recuperação do solo entre uma safra e outra, entre outras muitas práticas trocadas e repassadas entre os agricultores sem objetivo econômico, práticas realizadas tanto em pequenas feiras de sementes locais pelo interior do país quanto em grandes feiras como é o caso das Jornadas de Agroecologia pelo Brasil. 
As sementes, mantidas in situ, devem permanentemente ser trocadas, por isso quanto maior o intercâmbio, maior a possibilidade de manutenção. As Jornadas de Agroecologia propiciam este intercâmbio e fortalecem a figura do "guardião de sementes" que é a pessoa que guarda, reproduz, troca e conserva viva a cultivar, plantando e cultivando in situ.

As Jornadas de Agroecologia são encontros realizados em alguns Estados brasileiros, como Bahia e Paraná, entre os Movimentos Sociais do Campo, Organizações Não-Governamentais, Universidades, professores, pesquisadores e artistas do Brasil, da América Latina e Caribe. No Estado do Paraná as Jornadas de Agroecologia acontecem anualmente e de forma itinerante desde 2001 (MOREIRA et. al., 2018), ano em que nasceu sob o tema "Jornada de Agroecologia - Terra Livre de Transgênicos e Sem Agrotóxicos” (TARDIN, 2009). No caminhar da Reforma Agrária Popular Agroecológica novos temas foram se agregando ao debate nas Jornadas de Agroecologia, temas como a educação do campo, a saúde popular, gênero, LGBT, economia solidária nas cidades, cooperativismo, políticas públicas para o campo, mas sempre partindo da matriz agroecológica e das sementes crioulas.

Em 2018 a Jornada de Agroecologia completou sua 17 edição no Estado do Paraná e, pela primeira vez, foi realizada na cidade de Curitiba, com o objetivo de promover um encontro entre campo e cidade ${ }^{4}$. Apesar de muitas adversidades enfrentadas, no último dia da feira foi presenciada a importância dos guardiões de sementes para a conservação da biodiversidade e do conhecimento tradicional associado a ela quando um morador da cidade, a partir das sementes multiplicadas por ele em sua horta urbana, chegou para trocar uma espécie rara de semente com um guardião de sementes do MST. Eram quatro ou cinco grãozinhos de sementes do popularmente conhecido como "feijão mágico" que estava perdido. E o encontro entre guardiões de sementes do campo e da cidade aconteceu justamente na recuperação de uma semente tão querida e tão procurada pelos agricultores tradicionais. Uma vez recuperada a semente os guardiões têm a obrigação de reproduzi-las e distribuí-las, mantendo sua conservação e guarda in situ. Talvez por travessura do universo, sob o nome de "feijão mágico" se deu esta recuperação de perdida semente no improvável mundo humano/urbano, onde prolifera tudo, menos a biodiversidade. Magia que segue associada ao conhecimento tradicional para a conservação e multiplicação de semente e de vidas.

Jonas de Souza, camponês, produtor do Acampamento Agroecológico José Lutzenberger do MST, localizado na Mata Atlântica do Litoral Norte do Paraná, disse: “quem protege a natureza são as pessoas que nela vivem”. E é assim que os camponeses não indígenas se somam aos indígenas e demais populações tradicionais para provarem que os povos e os agricultores podem ter a magia do conhecimento tradicional que protege e multiplica a biodiversidade, com tecnologias simples, com muita interação com a natureza, com respeito às formas diversas de vida, produzindo principalmente para viver e dar de viver aos outros humanos e não humanos, sem preocupação com a riqueza acumulada em cofres e enaltecendo a riqueza da biodiversidade.

\section{CONCLUSÃO}

A vida do ser humano enquanto realidade físico-química e social demanda a satisfação de necessidades, para satisfazê-las é preciso agir sobre a natureza. Apenas a partir desta singela percepção da existência humana na terra percebe-se que a história da natureza e a história do ser humano, 
embora contraditórias, estão reciprocamente conectadas, e modificam-se incessantemente. A natureza e as relações sociais exigem o agir do ser humano, o ser humano se transforma constantemente nesse agir e novamente a natureza acaba modificada, em um movimento múltiplo. A forma como seres humanos produzem suas vidas depende dos meios já encontrados e que precisam reproduzir, depende da natureza que encontra e das relações sociais existentes, porém como ser humano é também teleológico pode também agir sobre a mudança, de forma que a consciência é determinada pela vida, da mesma forma que a vida pode ser transformada pela consciência.

Mediante a percepção do processo recíproco entre ser humano e natureza, como um pressuposto histórico indispensável da vida humana na terra, percebe-se a verdadeira natureza da biodiversidade: um complexo que envolve múltiplas determinações ecossistêmicas, as quais relacionam um processo milenar de adaptação de espécies a partir de condições bióticas e abióticas, incluindo fenômenos e condições climáticas, processo no qual a espécie humana vem assumindo impactos diversos que ocorrem há milhares de anos no planeta. Apenas mediante à percepção da grandeza que o fenômeno da diversidade biológica representa torna-se possível o desenvolvimento de estratégias passíveis de atuar em sua proteção e este consiste em um dos principais desafios para o Direito contemporâneo.

Desde as origens do sistema jurídico moderno o direito coloca-se no mundo como principal força legitimadora de processos sociais e econômicos pautados pela mercadoria. Isso ocorre principalmente mediante a abstração jurídica representada pela figura da propriedade e pelos aparatos de sua defesa. A partir do avanço das novas tecnologias emergiu a biotecnologia, que desafiou os regimes legais existentes de propriedade. Nesse cenário, a genética, os conhecimentos tradicionais e as espécies passaram a ser objetos de interesse comercial. A fim de elevar o status de propriedade desses aspectos tidos como recursos, é que o regime de propriedade vem sendo reformulado, não sem o impacto de conflitos ambientais ao redor da biodiversidade, os quais se expressam principalmente pelas alternativas de povos e comunidades tradicionais e camponeses.

No contexto em que as estratégias de conservação de recursos genéticos ex situ são amplamente rechaçadas, visto sua ineficiência, bem como em um quadro no qual a erosão da biodiversidade expressa um risco tanto para a vida no planeta em geral, quanto em particular para o avanço do capital biotecnológico, ações alternativas e ecossistêmicas de proteção da biodiversidade assumem grande potencialidade de impactar sobre a totalidade. Para além do interesse sobre os conhecimentos tradicionais e camponeses, aumenta a consciência sobre a dependência do desenvolvimento do capital biotecnológico e ambiental sobre a diversidade biológica inerente às formas de vida não capitalistas. Meio a esta realidade complexa e dialética na qual a biodiversidade é regulada pelo direito, as formas jurídicas assumem papel estratégico e seus sentidos e efeitos devem ser compreendidos enquanto parte desta realidade, a partir de um esforço crítico, diverso e complexo.

\section{NOTAS}

1 Sobre as Jornadas de Agroecologia do MST no Paraná ver: http://www.jornadaagroecologia.com.br/ 


\section{REFERÊNCIAS}

DIEGUES, Antonio Carlos (ORG). Os saberes tradicionais e a biodiversidade no Brasil. São Paulo: Ministério do Meio Ambiente, dos Recursos Hídricos e da Amazônia Legal, COBIO-coordenadoria da biodiversidade. NUPAUB-Núcleo de Pesquisas sobre Populações Humanas e Áreas Úmidas BrasileirasUniversidade de São Paulo, fevereiro de 2000.

FOLADORI, Guillerno; PIERRI, Naína (coord). ¿Sustentabilidad? Desacuerdos sobre eldesarrollosustentable. México: Universidad Autónoma de Zacatecas, 2005.

FOSTER, John Bellamy. A ecologia de Marx: materialismo e natureza. Rio de Janeiro: Civilização Brasileira, 2014.

FRANCO, José Luiz de Andrade. O conceito de biodiversidade e a história da conservação: da preservação da wilderness à conservação da biodiversidade.São Paulo: História, v. 32, n. 2, p. 21-48, jul/dez. 2013, ISSN 1980-4369.

INOUE, Cristina Yumie. Construção do conceito de regime global de biodiversidade e estudo do caso Mamirauá. O papel da comunidade epistêmica da biologia da conservação em experiências locais que visam conciliar conservação da biodiversidade e desenvolvimento sustentável, (UnBCDS, Doutor, Política e Gestão Ambiental, 2003).

MARX, Karl. O capital: crítica da economia política: livro I. Traduzido por Reginaldo Sant'Anna. 31 ed. Rio de Janeiro: Civilização Brasileira, 2017. Livro I, v. 2.

MATHIAS, Fernando. As encruzilhadas das modernidades: da luta dos povos indígenas no Brasil ao destino da CDB, p. 13-18. In: MATHIAS, Fernando; NOVION, Henry de. As encruzilhadas das modernidades: Debates sobre a Biodiversidade, Tecnociência e Cultura. São Paulo: Instituto Socioambiental, 2006.

MAYR, Ernst. O Desenvolvimento do Pensamento Biológico. Brasília: UnB, 1998.

MOAZOYER, Marcel; ROUDART, Laurence. História das agriculturas do mundo: do neolítico à crise contemporânea. São Paulo: Editora UNESP; Brasília: NEAD, 2010.

MOREIRA, Eliane Cristina Pinto; PORRO, Noemi Miyasaka; SILVA, Liana Amin Lima (orgs.). A "nova" Lei $n .^{\circ}$ 13.123/2015 no velho marco legal da biodiversidade: entre retrocessos e violações de direitos socioambientais. São Paulo: Instituto o direito por um Planeta Verde, 2017.

MOREIRA, Silvana dos Santos; VALADÃO, Adriano da Costa; SHIMANSKI, Édina; BRANDENBURG, Alfio. 14 ${ }^{\mathrm{a}}$ Jornada de Agroecologia em Irati, Paraná: espaço de resistência contra a criminalização dos agricultores executores do paa. Memórias e História da Agroecologia. Anais do VI CLAA, X CBA, X CBA e V SEMDF - v. 13, n.1, Jul. 2018.

PAIVA, João Rodrigues de. Conservação ex situ de recursos genéticos de plantas na região tropical úmida. Acta Amaz.[online]. 1994, v.24, n.1-2, p.63-80. ISSN 0044-5967. Disponível em: http://www.scielo.br/ scielo.php?pid=S0044-59671994000200063\&script=sci_abstract\&tlng=pt. Acesso em: 22 mar. 2019.

SANTONIERI, Laura and BUSTAMANTE, Patricia Goulart. Conservação ex situ e onfarm de recursos genéticos: desafios para promover sinergias e complementaridades. Bol. Mus. Para. Emílio Goeldi. Ciênc. hum. [online]. 2016, v.11, n.3, p.677-690. ISSN 1981-8122. http://dx.doi.org/10.1590/1981.812220160003 $\underline{00008}$.

SANTILLI, Juliana. A Lei de Sementes brasileira e os seus impactos sobre a agrobiodiversidade e os sistemas agrícolas locais e tradicionais. Boletim do Museu Paraense Emílio Goeldi. Ciências Humanas, v. 7, n. 2, p. 457-475, maio-ago. 2012.

SANTILLI, Juliana. Agrobiodiversidade e Direitos dos Agricultores. São Paulo: Editora Petrópolis, 2009.

SANTILLI, Juliana. Socioambientalismo e novos direitos: proteção jurídica à diversidade biológica e cultural. São Paulo: Peirópolis, 2005.

SCOTT, James C. Exploração normal, resistência normal. Revista Brasileira de Ciência Política. n. 5, Brasíliajan./ 
jul. 2011. Disponível em: http://www.scielo.br/scielo.php?script=sci arttext\&pid=S0103-33522011000100009. Acesso em: 17 jun. 2018.

SOUZA FILHO, Carlos Frederico Marés de. Conhecimentos tradicionais, consulta prévia e direitos territoriais. In: MOREIRA, Eliane Cristina Pinto; PORRO, Noemi Miyasaka; SILVA, Liana Amin Lima (orgs.). A "nova" Lei $n{ }^{\circ}$ 13.123/2015 no velho marco legal da biodiversidade: entre retrocessos e violações de direitos socioambientais. São Paulo: Instituto o direito por um Planeta Verde, 2017. p. 101-123.

TARDIN, José Maria. Jornada de Agroecologia: camponesas e camponeses em movimento construindo o sustento da vida e a transformação da sociedade. Revista Brasileira de Agroecologia, [S.1.], v. 4, n. 2, dec. 2009. ISSN 1980-9735. Disponível em: http://revistas.aba-agroecologia.org.br/index.php/rbagroecologia/ article/view/7762. Acesso em: 03 maio 2019.

WOOD, Ellen Meiksins. As origens agrárias do capitalismo. Revista Crítica Marxista, n. 10, ano 2000. São Paulo: Boitempo. p. 12-30.

Data de submissão do artigo: Maio de 2019

Data de aceite do artigo: Dezembro de 2019 